\title{
Fragile Visions of the Social: Rethinking Solidarity with the Performance Piece Faust and the TV-series Skam
}

\author{
Claudia Schumann ${ }^{1}$ (D)
}

Accepted: 15 July 2021 / Published online: 31 August 2021

(c) The Author(s) 2021

\begin{abstract}
The paper explores the portrayal of social relations among youth in the popular Norwegian TV-series Skam and places this analysis in relation to Anne Imhof's award-winning performance piece Faust, which received the Golden Lion at the 2017 Venice Biennale for the German Pavilion. As expressions of how today's youth experience social relations under the conditions of late capitalism, I examine the way in which the TV-series and the performance work respectively explore when and how 'we' is shaped. I argue that they provide particular insight into the limits and possibilities for the formation of relations of solidarity today.
\end{abstract}

Keywords Axel Honneth - Clare Hemmings · Affective solidarity - Sara Ahmed · Snap · Education · Nordic youth · Television - Anne Imhof · Faust · Performance art · Education for solidarity $\cdot$ Youth culture

\section{(Un-)doing 'We' Between TV and Performance Art}

How can we understand and conceptualize solidarity today? In which forms do we encounter it in our everyday lives? How are the conditions of solidarity, especially among the younger generation, presented and challenged in popular media and in the arts? I will discuss these and similar questions through engaging with the popular Nordic TV-Series Skam as well as with the performance piece Faust which won first prize for the German Pavilion at the 2017 Venice Biennale. The creator of the TV-series, Julie Andem, as well as the queer feminist performance artist Anne Imhof were centrally concerned with the way in which social relations are renegotiated under present conditions. I will argue that the explorations in their respective works are especially instructive as regards the disruptions of and conscious breaks with traditional forms and understandings of solidarity and the possibilities of new ways of forming and enacting relations of solidarity.

Claudia Schumann

claudia.schumann@edu.su.se; claudia.schumann@specped.su.se

Stockholm University, Stockholm, Sweden 
In both the performance piece and the TV-series, we find a portrayal and critique of the limits of liberal notions of freedom in a way which I relate to Axel Honneth's theorizations. Honneth argues that relations of interested solidarity form the necessary basis for social freedom beyond liberty and equality (Honneth 1996, 2008, 2014, 2017). In both works, furthermore, we also find interesting material for reflecting on the problematic limitations of Honneth's own notion of solidarity as well as ideas for how such a notion can be reworked and adjusted in order to accommodate contemporary conditions of dissolving traditional bonds in a hopeful manner. I will here use both Clare Hemmings' notion of "affective dissonance" (Hemmings 2012) as well as Sara Ahmed's notion of "snap" (Ahmed 2017) for the analysis of the way in which dissolving bonds and ruptures can become openings for the formation of new communities and forms of belonging. I will also employ the work of two Wittgensteinian feminists, Norval (2008) and Tanesini (2004) in order to further nuance the understanding of solidarity. Both the performance work and the TV-series, even though in varying degrees and from distinctly different perspectives, explore experiences of discomfort, disconnection and dissonance as a testimony to the present social reality and the dissolving of certain traditional bonds, but also in terms of their potential to propel other and new ways of associating, of forming bonds of solidarity and of acting together.

Before turning closer to the analysis of the way in which solidarities are undone and redone in Skam and Faust respectively, I would like to clarify how this particular TV-series and performance piece and their media forms can be understood in relation to the topic of this special issue. A primary motivation for choosing these works was the way in which both Skam and Faust appeal to an understanding of solidarity in terms of action in a way which clearly transgresses problematic uses of images whose primary intent is to arouse and encourage empathy (cf. Hållander 2019; Zembylas 2013) A second motivation was the specific use and embeddedness of social media in the two works. As Juliet Floyd has argued, the role of philosophy in relation to our emerging uses of technology and social media will increase in order to reinstate "overviews, situated, human perspectives" and thus reintegrating new media into meaningful life worlds. As she emphasizes, in the future "the point will be to focus, not on human-machine interaction, but on human-human significance in the presence of machines" (Floyd 2019, p. 718). This sketches also how I envision the contribution of my philosophical explorations in the present article.

The way in which I wish to engage with both Faust and Skam is not so much by suggesting a particular reading of the two works, nor in form of an exemplification of philosophical theories. Rather, I wish to discuss them as artifacts which themselves have acted as "philosopher-teachers" for me. Alexis Gibbs argues that "film can be educational in a broader sense than its current use in classrooms or lecture theatres for illustrative purposes" (Gibbs 2017, p. 268). Inspired by Stanley Cavell, he reclaims a notion of film as philosophy and as a "philosopher-teacher" (ibid.). In a similar vein I propose that Faust and Skam act themselves as "philosopher-teachers", as creating meaningful experiences because they "let a world happen" (Cavell 1979, p. 25), and not first and foremost to reveal or attribute a kind of underlying meaning or because they can serve to illustrate or explain a philosophical theory. 


\section{Tracing Solidarity in Axel Honneth's Critique of Liberal Political Theory}

One of the most prominent contemporary theorists of solidarity is the critical theorist Axel Honneth, who throughout his philosophical work in different variations is concerned with a critique of liberal political theory and argues for the necessity of thicker relations of mutual interestedness and social solidarity as the precondition of successful exercises of freedom. Since solidarity is so central to Axel Honneth's work, tracing the notion in its entirety is not possible, but I have selected some of the theoretical explorations that I consider most central to his thought.

The most thorough development, we can find in his first work, The Struggle for Recognition (1996), where Honneth develops a three-fold model of recognition within a Hegelian framework. After the development of the first form of recognition (love), which is based on a more personal, partial, and biased relationships to those who we form our early and later most intimate and private attachments to (parental figures, romantic partners, to some extent friendships), the second form of recognition, comparable to the liberal legalistic understanding of social relations, is in contrast highly impersonal, impartial, and subtracts all specificity and concreteness from the persons we relate to. In the realm of moral respect, we are all equal, we are to consider ourselves as equal only qua our humanity (and rationality) regardless of any subjective qualities that makes us specific individuals. In Honneth's understanding a society based on only this form of relating to each other, or social cohesion, is flawed and leads to pathological distortions. Social solidarity, as a third form of recognition necessary for human flourishing and our freedom, provides this. Our interest in the other person is here no longer as partial and based on intimate affection as it is in the realm of love (the first form of recognition), it is inflected by the dimension of moral respect, but is now again concerned with the specific contributions certain individuals our social groups contribute to society. Honneth is here concerned with professional as well as cultural groups. Unless we take an active interest with this third form of recognition, social freedom remains unachievable.

In his later work on Reification (2008), Honneth's ideas also have strong implications for our understanding of solidarity. The notions he works with here: care, acknowledgment, etc. are placed at a different ontological level than in The Struggle for Recognition. In cases of reification, is solidarity then totally impossible? Arguably, yes. Here our basic capacity, for acknowledging others as human beings and not just things, exchangeable goods for our instrumental use, has been lost or forgotten due to an elongated practice that encourages this non-acknowledgment. Here, I discuss what Honneth himself suggests in terms of remembering, but also how these practices are ultimately unlivable (if we want this or not, if we know this or not). Here, Hemmings' article becomes interesting because she gives one example of how unlivable practices and loss of solidarity can actually not just be destructive, but can push one to find livable practices and solidarity elsewhere (we mention this here and develop further down).

In The Right to Freedom (2014) Honneth's arguments for social freedom are quite similar to the Hegelian argument in The Struggle for Recognition as well as in his critique of the liberal, legalistic model. However, here he develops an internal critique from within existing social forms in order to demonstrate that we actually already rely on forms of social freedom to an extent that in our very own practices counters and disproves the liberal model. He works more descriptively here and it is no longer any question of mis-recognition being 
the motivator for recognition; the strategy now is more to show that in our existing practices we already rely on forms of social freedom (he has a long discussion on friendship, for example), which go beyond the liberal model and without which our social life would not be what it is. However, it is not unjustified that he has been accused for producing a rather conservative critique here (in the literal not necessarily political sense), since it is not grounded in pain and the normative grounds for minority groups to struggle for equal rights any longer, but based on an affirmation of rather contingent present legal conditions in western (social) democracies. What if things were otherwise? How would we then be able to write the critique?

In his latest work Socialism (Honneth 2017) the concrete political-historical underpinnings of his thinking are made most explicit. His idea of social freedom is closely tied to the French socialist thought tradition, as well as to the social democracy model of (most exactly pre-neoliberal) Germany. In both senses, it becomes obvious that his model of social freedom remains tied to and limited by the nation state. He even says this explicitly himself that he rejects the idea that his thoughts could usefully be employed in a global frame. In contrast, I argue, that this is necessary and also possible. From a Hegelian framework, Honneth argues convincingly for solidarity as social freedom. We need to go beyond the legal, liberal rights framework in order to arrive at a meaningful notion of freedom. However, he sticks mostly to a national framework and his idea of social organization remains restricted to a model of the German welfare state. In today's world, however, other models are necessary, and we need to extend his analysis to think heterogenous and transnational interrelations as the restriction of thinking relations of solidarity on the national level are no longer sufficient in a time of growing global challenges and intersectional overlaps. Honneth's distinction between love and solidarity is valuable and will inform the further discussion below when I explore the important differences between empathy and solidarity in education. Another shortcoming I see in the work of Honneth is his acknowledgement but limited engagement with feminist and postcolonial work on recognition. While Honneth certainly shows admiration and respect for these perspectives in his work, it is not followed through with deeper engagement with the writings. I will sketch why this could be fruitful with the example of his discussion of recognition between empathy and solidarity and the feminist approaches I will discuss in the following.

\section{Saying 'We' Beyond Agonism and Deliberation: Reworking Honneth with Norval and Tanesini}

A first adjustment to Honneth's theory that I would wish to suggest is through the work of the Wittgensteinian feminist thinkers Alessandra Tanesini and Aletta Norval. Expanding the thought of Wittgenstein and the interpretations by Stanley Cavell, Tanesini argues that acts of saying 'we' function as acknowledgments which help us expand and change "our attunement in words, emotions and reactions" (Tanesini 2004, p. 137), and to test and realize the depth and breadth of these attunements. While this might appear as a trivial thing at first sight, but without these (primary) attunements we could not agree or disagree with one another. By means of projective imagination, acts of saying 'we' help us to expand and change the nature of such attunements (cf. Tanesini 2004, p. 137). We learn and we are taught, and we teach how to use words in specific, and limited contexts. But we also learn 
how to project words into new and different contexts, and we expect this ability to project in everyday interactions with others: "the application of a word is not everywhere bounded by rules" (PI I § 84) (Wittgenstein 1953/2009). Nevertheless, we distinguish between correct, meaningful and incorrect, senseless projections. In contrast to the consensus-oriented, deliberative model of communication as well as in distinction from Chantal Mouffe's agonistic model, Tanesini suggests a different way of saying 'we'. As she writes:

some acts of saying 'we' function as expressions of acknowledgement of your claim on me. They are not intended to assert that there is something that we have in common; rather, they are one of the ways in which we recognize the claims made upon us by others. (Tanesini 2004, p. 127)

While Honneth's model of solidarity as a third form of recognition, especially in the early idea of struggle for recognition, is itself positioned in some distance to the Habermasian deliberative model, the relations of recognition discussed and envisioned by Honneth often implicitly presuppose a silent 'we' of a majority who hears appeals for recognition by different social minorities. In Tanesini's model the respective 'we' under negotiation is not one of a majority becoming more and more inclusive. It is far more fragile, dynamic, and under continual renegotiations.

Tanesini's approach provides a fruitful entry into understanding why understanding 'we', or social solidarity, in terms of communities of battle (Mouffe) is equally insufficient and an ultimately egotistic form of solidarity as the deliberative model of understanding our saying 'we'. In a comment to his close friend Maurice O'Connor Drury, Wittgenstein pithily remarked: "Hegel seems to me to be always wanting to say that things which look different are really the same. Whereas my interest is in showing that things which look the same are really different." (Rhees 1990, p. 536-537). In a sense we can say that Tanesini's framework, with Wittgenstein, introduces further differences into Honneth's Hegelian perspective. On the other end of the spectrum of models of communication, Mouffe articulates her understanding of an agonistic democracy: "It is vital to recognize that, since to construct a 'we' it is necessary to distinguish it from a 'them', and that all forms of consensus are based on exclusion, the condition of possibility of the political community is at the same time the condition of impossibility of its full realization" (Mouffe 1995, p. 36). However, with Tanesini we can ask whether it is correct that saying 'we' truly always implies drawing boundaries that demarcate the "frontier" (Mouffe 1992, p. 379) between us and them. Honneth, in contrast, already in Struggle for Recognition, is rather careful that 'we' is always inflected by difference, even in the realm of love (which is conceived rather ahistoric but not without internal difference). Nevertheless, his model still remains Hegelian in the way of the 'we' of the majority becoming expanded and more inclusive. In Tanesini's Wittgensteinian understanding, the 'we' and our mutual attunements and acknowledgment is continually tested and reconfigured. Another interesting approach that subscribes to a similar position as Tanesini and emphasizes that our ways of saying 'we' are not restricted to defining us against them (difference with a big D) or to deliberative models ('consensus') has been proposed by Aletta J. Norval in Aversive Democracy (2008). As Norval states:

Democracy and democratic identity are not given once and for all, fully constituted and then simply subject to administration. To the contrary, $[. .$.$] democracy is to be$ conceived of as an ongoing project of renewal. (Norval 2008, p. 18) 
She proposes a constant call for trying to make ourselves intelligible to ourselves and others even when claims we raise or are confronted with are a challenge to existing democratic grammar or can presently not even be registered within it. She emphasizes the importance of imagination and exemplarity for illustrating possibility of a further self as well as a further community beyond present state of affairs.

\section{Affective Dissonance and Snap: Reworking Solidarity with Hemmings and Ahmed}

After introducing Honneth's arguments for the importance of cultivating relations of solidarity in order to attain social freedom beyond the idea of liberty and equality of political liberalism, I have taken a first step in problematizing and reconfiguring Honneth's understanding of solidarity with the help of Norval and Tanesini. In a second step, I will now will consider Honneth's writing further in relation to the work of Clare Hemmings on affective solidarity and to the work of Sara Ahmed on the notion of "snap". The reason for introducing these two thinkers is that they can make a valuable contribution and give a plausible analysis in light of the question why relations of solidarity, or mutual interestedness and affiliation, can break, and that - at least in some cases - the dissolution of (traditional) bonds of solidarity can also propel new forms of affiliation and the creation of new bonds of other solidarities.

Clare Hemmings' idea of feminist reflexivity and affective solidarity (rather than care) as sometimes emerging out of affective dissonances in women's experience can be related to Honneth's idea of claims and struggles for social freedom as deriving out of experiences of misrecognition. However, in Honneth the struggle for recognition moves from the misrecognition of minorities toward the recognition by the majority 'we'. In Hemmings, the focus is on the dissonance in women's experience leading to the break with a majority 'we' and then to the initiation of new alliances, of new solidarities of joint protest, struggle or just alternative association. Hemmings imagines "a politics that begins with experiences of discomfort" (Hemmings 2012, p. 158) and that then, through a reflexive politicization, might lead to seeking solidarity. She argues that reflexive politicization as a result of affective dissonance can become the basis for seeking "solidarity with others, not based in a shared identity or on a presumption about how the other feels, but on also feeling the desire for transformation out of the experience of discomfort, and against the odds" (Hemmings 2012, p. 158). As Hemmings further specifies:

Thus standpoint as I have reimagined it here describes not just marginal experience and the critique of dominant knowledge, but the process of moving from affective dissonance to a struggle for alternative values, and even perhaps to a mutual recognition and affective solidarity (maybe even one that includes empathy). (Hemmings 2012, p. 157)

Similar to Honneth' conception, Hemmings' notion of affective solidarity is not a solidarity ofmere feeling, but it is an active doing, a practice that might be sparked by affective dissonances but is not exhausted by affect and emotion and does not end there.

A further theoretical perspective which I find helpful to critically extend Honneth's notion of solidarity is cultural theorist Sara Ahmed's figure of "snap". She describes this as a breaking point which women, queers or people of color can reach in relation to interact- 
ing with and trying to adapt to the norms of an oppressive majority. However, this breaking point is not a point of resignation or a merely negative breaking away from tradition, earlier relations, or with established norms. As Ahmed writes, "For me, the snap was not the sad point. It was rather relief from pressure" (Ahmed 2017, p. 194). So, while experiences usually build up over a long time continuously before the snap happens, in this sense a snap is an end of something, it can also propel something new: "A snap is not a starting point, but a snap can be the start of something." (Ahmed 2017, p. 194) The "snap" or to "snap" can imply a taking back of control, a regaining of energy and being able to tap into completely new resources after breaking away from and lifting the pressure of unhealthy, oppressive, stifling relationships.

Furthermore, this snap is not a mere individual experience. This is actually a part of the idea of the snap not being a starting point. A feminist snap is defined "not as a single moment of one woman experiencing something as too much, but as a series of accumulated gestures that connect women over time and space" (Ahmed 2017, p. 200). In that sense the "snap" can also describe collective experiences and endeavors, especially if the disruption of oppressive norms leads to a collective break away from as well as a turning toward the forming of new collectives and working in solidarity for overcoming our oppression. As Antonakaki et al. summarize, the snap can "orient our attention backwards from their explosive 'present' and towards figuring out that the point of origins does not lie in the incident itself” (2018, p. 927). They further explain how the snap becomes a complementary link between what they call Ahmed's "feminist pedagogy" and "feminist genealogy":

the feminist snap is a type of shared lesson-in-feminism and an extended and unconventional kinship-making. Concerning the former, this is the provocation and promise of calling 'feminist pedagogy' an equation: the moment of mutual recognition makes us equal, as we recognise how we have all been there before, over and over, and most probably will find ourselves back there in the future. In a complementary mode, $[\ldots]$ lies the invitation of the 'feminist genealogy' as a category that allows revisiting the lived experience of snap but not from a solitary point of view. This is a future-oriented genealogy stemming out of bonds we choose and in the face of the inescapability of snap experience within institutions we live and work at. (Antonakaki et al. 2018, p. $927 \mathrm{f}$.)

The pedagogy of the "snap" also implies a moment of mutual recognition, but the central focus here in Ahmed is not on the insight or the empathy brought forth in the silently presupposed 'we' of a normative majority. This understanding of snap as releasing the educational potential of collective experiences and sharings of "snap" and as in this way grounding active work of solidarity beyond empathy can be related to Ahmed's earlier texts on emotion (Ahmed 2004) and give further support to Marie Hållander's analyses which problematized the use of emotion and empathy in education (Hållander 2019) while holding tight to the pedagogical ambition of enabling "change to different injustices or structural discriminations" (Hållander 2019).

In the following concluding paragraphs, I will try to show in which way Skam and Faust can teach that Hemmings' and Ahmed's analyses are not restricted to feminist affective solidarities and to feminist snaps, but can be extended to a hopeful vision for educational practices that enable and encourage the forming of solidarities in ways where the breaking and the snaps can have positive, renewing and rearranging effects beyond what the Hon- 
nethian model allows for while preserving his important critique of the liberal understanding of freedom.

\section{Shifting Educational Practices: Skam and Faust as "Philosopher- teachers"}

After the theoretical exploration of Honneth's model of solidarity and possible adjustment through the feminist approaches I now want to turn in more detail to how different relations of solidarity are enacted in the TV-series Skam and in the performance piece Faust; how they portray prospects for the cultivation of such relations respectively and in which ways both works embody an education in solidarity.

In the Norwegian teenage series Skam contemporary forms of solidarity are explored in at least two dimensions. The series follows one character in each season and explores individual perspectives, e.g. the specific challenges of Muslim or LGBTQIA students, but not just by becoming representative for the struggles of a respective minority group. The teenagers' discord with mainstream school culture become openings for the formation of new communities and forms of belonging. The students long for and depend on supportive friendships and a social role in a group of peers that exceeds instrumental relations. These bonds are presented as precondition for the flourishing and the exercise of personal liberties for each and every individual character. Ultimately painting a vision of an educational social development clearly informed by the social democratic tradition in the Northern countries, the individual differences of the students find their legitimate place in a model of solidarity and conviviality. The series becomes educative and pedagogical in its intersectional understanding of different forms of social exclusion, and the way in which a world transformed into a more socially just world is thought possible. In a similar way as in Faust, and based on thorough interviews and research in advance of the production of the series, new media have a prominent place in the TV-Series Skam. This is the case not only in the interactions on- screen between the characters, but also in the way in which the audience is invited to participate in the series. There is an encompassing performative element in how the audience becomes involved. Intentionally addressing youth rather than a traditional TV audience, the production invites the audience to follow the series in different forms and on different distribution platforms, and they can respond to and interact with and are invited to be involved with the story through different forums and social media.

Anne Imhof's critics describe her portrayal of contemporary social reality as follows: "Aimless individuality persists even as it clusters into groups. They may sing together, but their song is of the "I'" (Pfeffer 2017, p. 10). Another critic observes that: "The alienation that is at issue here is no longer that between subjects and things; it is one between the subject and it-self-as-agent." (Rebentsch 2017, p. 28 f.). This diagnosis paralleled the analysis of the relevance that a renewed look at the critique of reification has for understanding the production of a specific form of Teilnahmslosigkeit ('participatorilessness') under the conditions of present neoliberal global capitalism (Honneth 2008; Chari 2015; Schumann 2020). If performance art in the $1970 \mathrm{~s}$ was devised in order to transgress the structures of commodification in the art market, Imhof now uses the same medium so as to show the impossibility of escape. What remains is to illustrate the "the perversion of the euphoric sense of possibility into a feeling of emptiness" (Rebentsch 2017, p. 29). Imhof's particular 
use of technology for the instructions and changes between different scores for the performers underlines the critical engagement with new media in her work. This is also echoed on a material basis by the plexiglass walls barring the entry to the pavilion and structuring the inside of the building, adding transparent yet impenetrable walls, floors and ceilings. Nevertheless, the piece does not need to be read as stopping at the bleak portrayal of alienated (or reified) social relations. The intentional non-engagement of the audience, the being confronted with consumable, beautiful images, as if distant memories of a protest culture, rather than a performance which involves the audience in transformational experience, also affects the audience. The ensuing experiences of discomfort, disconnect and dissonance are not just testimony to the dissolving of bonds, but they have the potential to propel other and new ways of associating, of forming bonds of solidarity.

In the introductory paragraphs I suggested a reading of the TV-series Skam as well as of the performance piece Faust not as mere illustrative examples of philosophical, theoretical analyses and commitments, but rather as themselves "philosopher-teachers". What then is it that both works teach? What are the implications and consequences for a pedagogy of solidarity in what is possible to experience in the world that Skam and Faust let happen? In both cases, we find ourselves in worlds which clearly display the shortcomings and challenges of our contemporary reality and portray the necessity for reconfiguring and reinventing the conditions of social relations and collectivity in terms of an interested, mutual solidarity. The worlds of Skam and Faust do not lack in material riches, but their inhabitants suffer from a specific form of reified subjectivity produced by contemporary capitalism, which can be described as a problematic form of disengagement- "Teilnahmslosigkeit" (Honneth 2008; Chari 2015; Schumann 2020), and which radically impacts the conditions of possibility of a democratic politics. In Faust, the performers, for the most part of the piece isolated in their respective individual scripts, relate to each other solely in terms of different power dynamics, confronting "the brutality of our time with a hard realism" (Pfeffer 2017, p. 10). In Skam, the whole series is started off with a student essay critically reflecting on the consequences of contemporary capitalism, and the children's existence is shown as distinctly shaped through parental absence compensated materially, by competition within the classroom and defined by various patterns of consumption.

Moments and narratives of promise are developed continuously throughout the different seasons in Skam. These moments are somewhat sparser, more complex and hidden in Faust. In Skam, we find very little traditional solidarities along the lines of groups such as unions, around class struggle, feminist struggle. The way in which 'we' is negotiated here is more portrayed in the way that Norval and Tanesini describe, as a continuous renegotiation and reconfiguration of who belongs to a we created between a you and and I, and a continuous testing of whether a 'we' holds or needs to be reformed. Furthermore, we are allowed to follow the different characters to their points of affective dissonance and snap until the point where different and new solidarities are formed and spark different kind of actions.

In Faust, the hopeful perspectives are more intricately placed. Rebentsch describes the specific strategy employed in Faust as follows:

Imhof's works stay true to the emancipatory promise of an unfixable difference, the promise of an un-reified queerness, not in some kind of 'artistic' excess over its domesticated version meant to establish a zone of authenticity against the corrupted rest but, on the contrary, by worming their way into the state of alienation such that it becomes perceptible and can gradually be set at a distance. Alienation is accordingly 
neither the object of an explicit critique nor exhibited with a clinical air, as though a standpoint external to it were possible; distance, here, instead derives from the experience of alienation's patterns. Imhof's genius for abstraction lies in the way she distills the universal from the particular, the social from the psychological, the quotable gesture from the ostensibly individual expression, in short: in performing the mimesis of alienated life as an assimilation to an objective reality. (Rebentsch 2017, p. 28)

The pedagogy of solidarity which is used in Faust does not work as a classical emancipatory pedagogy explaining and revealing a more truthful account of reality underlying that which we perceive in our everyday experience. Neither does it contrast the way social relations are formed and organized now with a non-reified, better way. What then is the way in which Faust engages with the question of community? Curator Susanne Pfeffer proposes an interesting analysis of the way music is employed by Imhof:

The sound of compositions resonates, specifically created for each of the performers' voices. At first, they are scattered across the room, eventually coming together as part of a technological network of mobile phones and building into a formidable solipsistic choir. Aimless individuality persists even as it clusters into groups. They may sing together, but their song is of the 'I'. (Pfeffer 2017, p. 10)

But it is not just the "solipsistic choir" that highlights the way in which a community of solidarity is shown as absent and failing in the present, while referencing the aesthetic codes of squatters (climbing and taking over the German Pavilion) and a revolutionary music scene. It is also present in the way that Imhof specifically refrains from engaging the audience in a participatory form common to performance work. She confronts the audience with beautiful and captivating images, but there is no apparent moment of involvement, of attempting to touch, involve and transform the audience, or to transgress the barrier between performer and audience:Rather than positing self-contained worlds before an audience, she creates situations in which spectators become attendees who, if simply by virtue of their positions and movements in the space, exercise a latent influence over what happens. However, this influence should not be mistaken for some sort of participatory 'involvement' of the audience in the performative work. No community comes into being here. (Rebentsch 2017, p. 30)

Only interrupted in rare moments of short improvisation, a small gesture or gaze appearing to search for something more, more human, in the connection with the co-performers or the audience, all forms of resistance, difference and deviation, e.g. the androgynous, queer or gender neutral look of the performers, are shown as already having become fashionable and consumable. Not even the form of performance itself keeps its promise of an (at least temporary) escape from reification with its insistence on the importance and presence of the live body as well as on an art form that intends to resist its own commodification (Dolan 2005; Muñoz 1999). As Rebentsch describes, it is Imhof's goal to "confront the spectator with the shocking absence of living abundance" (Rebentsch 2017, p. 28) in contrast to the time of Hannah Arendt who still held that a person's aliveness functions as a form of excess, an abundance that goes beyond "all generalization and therefore all reification" (ibid., p. 27). Today's capitalism has shifted from standardizing subjects to exploiting (domesticated) differences and "all living presence is undercut, also and especially the presence of the performance" (ibid., p. 28). In this way, "the performance itself comes into view as a commodity 
fetish" (ibid.). This coming into view is possible because the world that Faust immerses the audience into lets us experience performance and makes it visible as commodity fetish. But Imhof does not just portray reified social relations or dissolved solidarities. This coming into view also opens for the kind of affective dissonance or snap which Ahmed and Hemmings describe so pithily as opening up for the possibility of new kinds of solidarity forming. For a contemporary conception of ethico-political education, both Skam and Faust suggest that we renew a politicized and social understanding of Bildung, which leaves the traditional individualistic premise behind and makes serious effort to spell out the relational conditions of self-cultivation.

Funding Open access funding provided by Stockholm University.

Open Access This article is licensed under a Creative Commons Attribution 4.0 International License, which permits use, sharing, adaptation, distribution and reproduction in any medium or format, as long as you give appropriate credit to the original author(s) and the source, provide a link to the Creative Commons licence, and indicate if changes were made. The images or other third party material in this article are included in the article's Creative Commons licence, unless indicated otherwise in a credit line to the material. If material is not included in the article's Creative Commons licence and your intended use is not permitted by statutory regulation or exceeds the permitted use, you will need to obtain permission directly from the copyright holder. To view a copy of this licence, visit http://creativecommons.org/licenses/by/4.0/.

\section{References}

Ahmed, S. 2004. The Cultural Politics of Emotion. New York: Routledge.

Ahmed, S. 2017. Living a Feminist Life. Durham, N.C.: Duke University Press.

Antonakaki, M., J. E. French, and C. Guner. 2018. Realising Sara Ahmed's 'feminist snap'. Ephemera 18 (4): 923-954.

Cavell, S. 1979. The Claim of Reason. Wittgenstein, Skepticism, Morality, and Tragedy. New York/ Oxford: Oxford University Press.

Chari, A. 2015. A Political Economy of the Senses. Neoliberalism, Reification, Critique. New York: Columbia University Press.

Dolan, J. 2005. Utopia in Performance: Finding Hope at the Theater. Ann Arbor: University of Michigan Press.

Floyd, J. 2019. Teaching and Learning with Wittgenstein and Turing. Journal of Philosophy of Education 53 (4): 715-733.

Gibbs, A. 2017. What Makes my Image of Him into an Image of Him? Philosophers on Film and the Question of Educational Meaning. Journal of Philosophy of Education 51 (1): 267-280.

Hållander, M. 2019. On the Verge of Tears: The Ambivalent Spaces of Emotions and Testimonies. Stud Philos Educ 38: $467-480$.

Hayes, J., ed. 2017. The Selected Writings of Maurice O'Çonnor Drury. London: Bloomsbury Academic.

Hemmings, C. 2012. Affective Solidarity. Feminist Reflexivity and Political Transformation. Feminist Theory 13 (2): 147-161.

Honneth, A. 1996. The Struggle for Recognition. The Moral Grammar of Social Conflicts. Cambridge, MA: MIT Press.

Honneth, A. 2008. Reification. A New Look at an Old Idea. Oxford: Oxford University Press.

Honneth, A. 2014. Freedom's Right. The Social Foundations of Democratic Life. Cambridge: Polity Press.

Honneth, A. 2017. The Idea of Socialism. Towards a Renewal. Cambridge, UK: Polity Press.

Mouffe, C., ed. 1992. Dimensions of Radical Democracy. London, New York: Verso.

Mouffe, C. 1995. Politics, democratic action, and solidarity. Inquiry: An Interdisciplinary Journal of Philosophy 38 (1-2): 99-108.

Muñoz, JE. 1999. Disidentifications. Queers of Color and the Performance of Politics. Minneapolis: University of Minnesota Press.

Norval, A. J. 2008. A Democratic Politics of Acknowledgement. Political Judgment, imagination, and exemplarity. Diacritics 38 (4): 59-76.

Pfeffer, S. 2017. In a Solipsistic Choir. In Anne Imhof. Faust, ed. S. Pfeffer, London: Koenig Books. 
Rebentsch, J. 2017. Dark Play. Anne Imhof's Abstractions. In Anne Imhof. Faust, ed. S. Pfeffer, London: Koenig Books.

Rhees, R., ed. 1990. (Ed.). Recollections of Wittgenstein. Oxford: Oxford University Press.

Schumann, C. 2020. becoming things, becoming-world. Stockholm: Stockholm University Press.

Tanesini, A. 2004. Wittgenstein. A Feminist Interpretation. Cambridge, UK: Polity Press.

Wittgenstein, L. 1953/2009. Philosophical Investigations. Wiley-Blackwell. (PI), Oxford.

Zembylas, M. 2013. The "Crisis of Pity" and the Radicalization of Solidarity: Toward Critical Pedagogies of Compassion. Educational Studies 49 (6): 504-521.

Publisher's Note Springer Nature remains neutral with regard to jurisdictional claims in published maps and institutional affiliations. 